\title{
Remembering Alina Kwiatkowska
}

Alina Kwiatkowska graduated from the University of Lodz in late seventies of the past century. I was not her teacher but I vividly remember Professor Tomasz P. Krzeszowski, then head of the Department of English Language and Alina's PhD supervisor later, going out of his office in Kosciuszki 65 and pointing to me a delicate, red-haired girl who was sitting at a desk in our common room - 'She's the best student at my seminar' I heard from him. And she was indeed - Alina grew into one of the best cognitive linguists I've ever met, knowledgeable, sensitive, creative.

Professor Alina Kwiatkowska observed that moving of meaning across the borders can help find a substance which emerges in such a motion, the substance - combined or juxtaposed - which can make up an enthralling, often unexpected, whole. Ala or Alusia, as we used to call her, was one of the first to recognize Mitchell's 'pictorial turn' happening in our times. She was also one of the first to identify 'the ecstatic embrace of verbal and visual', as Anne Keefe describes it.

Alina Kwiatkowska earned her doctoral degree and completed her dr habil. and professorial procedures at the University of Lodz. Both her scholarly interests as well as classes, lectures she taught, conferences and seminars she organized focused on language-vision semiosis and the role language plays when combined with picture. She supervised over one hundred MA theses and a number of doctoral dissertations and was instrumental in establishing the Student Research Circle Texts and Codes, which organized national PhD student conferences in Lodz. Alina pursued a number of innovative projects, often in collaboration with colleagues from Lodz literature departments.

Alina Kwiatkowska was also one of the founders of the Polish Cognitive Linguistics Association and served as its President for one term, attracting new members with original, fruitful activities. 
In the past twenty years or so, Ala shaped the debates at the interface between the verbal and visual both at the Lodz department and in cognitive linguistic circles. She believed that better theories of language - and communication - would come from the interaction between these two modes, which can also provide deeper access to wider ranges of subtle linguistic data. As early as 1986, when she defended her PhD, Ala clearly saw an incompatibility of generative theories of language, then in full bloom, to the research questions she pursed and to what started being widely accepted in linguistics only a few years later.

I was happy to organize with Ala an international conference on Imagery in Language at the University of Lodz. The conference was dedicated to Professor Ronald Langacker and his honorary doctorate he was awarded by the University of Lodz in 2002. The volume we co-edited can be considered a state-of-the art survey of Cognitive Linguistic Research of Its Time.

Professor Alina Kwiatkowska was also employed at Jan Kochanowski University in Piotrków Trybunalski. There too she organized cyclic international conferences, this time focusing on Humor. Theories - Applications - Practices, with a few post-conference volumes published and widely read. She was also an author of the project Hybrid Identities. Hybridity in Literature, Language, and Culture, which paved her way to the International Comparative Literature Association and their congresses. Ala's presentation on The Application of the Theory of Conceptual Integration in the Study of Hybrid Identities and her conclusions are likely to shape the debate on these issues today and in the future.

Alina Kwiatkowska's genuine interest in art was seen in her engagement in translation, which she performed cooperating with Lodz Museum of Arts and Art Gallery. She was also member of the Advisory Board and language editor of Art Inquiry, a periodical published by Lodz Scientific Society.

Alina Kwiatkowska was a prolific author of studies on verbal and nonverbal character of communication in such papers as Cross-modal Translations: The Visual into the Verbal (1996), Between the Metaphoric and the Metonymic Pole: The Modes of Modern Art (2000), and her particularly ingenious variations on Magritte'a work A Non-pipe and Other Dubious Objects. The Trickstery of Images (2012).

The language of poetry was a special area of Alina's research. Her papers On the Concreteness of Poetry (2004), Defamiliarization Revisited: Noncanonical Construal in Poetic Texts (2004), editorial work on Texts and Minds. Papers in Cognitive Poetics and Rhetoric (2012), are stimulating examples of 
her scholarly taste. Japanese language and culture, haiku poetry, appear as unexpected areas in what stood up as genuine intellectual values.

Interpreting sensual perception and feeling as expressed in language in her paper A Look at Smells and Tastes and Their Reflection in Language in 2002, an important 2008 work on perceiving and expressing resemblance in language, or the paper focusing on linguistic strategies of avoiding responsibility ('The Devil Made Me do It!'. Some of the Things We Say to Push the Blame away from Ourselves, 2008), or else an international conference and the post-conference volume on Fifty Years with The Beatles. The Impact of The Beatles on Contemporary Culture (2010), are just small samples of the originality of Alina Kwiatkowska's research questions, her imagination and the unique ways to respond to them.

The present collective volume Moving between Modes. Papers in Intersemiotic Translation starts with an editorial Alina managed to write, although she did not fully complete the editorial work. The volume is a logical continuation of her whole scholarly career. Devoted to intersemioticity of translation and the media, and their characteristics, Alina managed to collect contributions of insightful analysis which point to a variety of semiotic differences between source medium and target medium, literature, picture, music, and film, that permit alterations into novel creations, the transformations which are immanent in the interconnected media.

Alina was a scholar of great intelligence and erudition, she was a creative person filled with surprising and unconventional taste such as painting, music and poetry. She was a poet herself, wrote limerics, painted subtle watercolours and listened to rock music. She was particularly fascinated by abstract and nonsense art but also discovered sense in ordinary things like chairs, which served as a topic of one of her brilliant cognitive analyses.

To her students and colleagues, Alina was an inspiring mentor, always ready to help a student or colleague, and when required she fought with tenacity for the causes she knew to be just. She acted quietly taking on burdens without ever seeking any recognition.

On $4^{\text {th }}$ May, 2018, Alina Kwiatkowska passed away, unexpectedly for us and prematurely. Intelligent and rigorous as a scholar, curious and exemplary in her teaching and mentoring of students, inspirational and courageous and, at the same time, fragile, modest, and non-imposing, we miss Alina and will not forget her values and dedication. 